\title{
Dendritic Cells and Their Role in Cardiovascular Diseases: A View on Human Studies
}

\author{
Maja-Theresa Dieterlen, ${ }^{1}$ Katja John, ${ }^{1}$ Hermann Reichenspurner, ${ }^{2}$ \\ Friedrich W. Mohr, ${ }^{1}$ and Markus J. Barten ${ }^{2}$ \\ ${ }^{1}$ Department of Cardiac Surgery, Heart Center, Helios Clinic, University Hospital Leipzig, 04289 Leipzig, Germany \\ ${ }^{2}$ Department of Cardiovascular Surgery, University Heart Center Hamburg, 20246 Hamburg, Germany
}

Correspondence should be addressed to Maja-Theresa Dieterlen; mdieterlen@web.de

Received 23 November 2015; Revised 22 January 2016; Accepted 22 February 2016

Academic Editor: Silvia B. Boscardin

Copyright (C) 2016 Maja-Theresa Dieterlen et al. This is an open access article distributed under the Creative Commons Attribution License, which permits unrestricted use, distribution, and reproduction in any medium, provided the original work is properly cited.

\begin{abstract}
The antigen-presenting dendritic cells (DCs) are key to the immunological response, with different functions ascribed ranging from cellular immune activation to induction of tolerance. Such immunological responses are involved in the pathophysiological mechanisms of cardiovascular diseases, with DCs shown to play a role in atherosclerosis, hypertension, and heart failure and most notably following heart transplantation. A better understanding of the interplay between the immune system and cardiovascular diseases will therefore be critical for developing novel therapeutic treatments as well as innovative monitoring tools for disease progression. As such, the present review will provide an overview of DCs involvement in the pathophysiology of cardiovascular diseases and how targeting these cells may have beneficial effects for the prognosis of patients.
\end{abstract}

\section{Introduction}

Dendritic cells (DCs) and their antigen-presenting properties possess a central role in the immune system, with many diseases associated with a heightened immune response. Among these, cardiovascular diseases (CVDs) represent the most frequent causes of death worldwide, with an estimated 17.3 million deaths per year [1]. While most research has been done in the field of heart transplantation, more recently, DCs were also shown to be involved in numerous other CVDs. This present review, therefore, will discuss the underlying role of DCs in the immunological mechanisms that underpin the development and progression of CVDs. In contrast to previous reviews, the present essay will focus exclusively on human rather than animal studies, as the different phenotypical and functional DC subsets between groups [2] can often lead to misleading conclusions.

\section{Immunological Mechanisms}

DCs patrol the blood and peripheral tissue to detect foreign and pathogenic antigens. According to their hematopoietic origin, DCs can be divided into myeloid DCs (mDCs) and plasmacytoid DCs (pDCs). Additionally, numerous surface markers have been shown to be useful for the identification of multiple DC subsets. For example, blood dendritic cell antigens (BDCA1-BDCA4) can be used to discriminate among DC types [3, 4], while further markers can also classify DCs such as S100 (expressed in mature and immature DCs), CD1a (expressed mainly in immature DCs), and CD83 (expressed mainly in mature DCs). Furthermore, specialized "cardiac" DCs have been found in the human heart [5-7], with immunohistochemical and morphological analyses revealing a subtype of DC expressing human leukocyte antigen(HLA-) DR (but not S100, CD1a, CD21, CD23, and CD35 [5]). This different surface marker profile compared to ordinary DCs therefore led to the hypothesis that cardiac DCs change their characteristics depending on their location either in the blood vessels or in the heart [5].

The detection of foreign or pathogenic antigens (pathogen-associated molecular patterns, PAMPs) as well as tissue damage and inflammation (damage-associated molecular patterns, DAMPs) leads to phagocytosis of antigens by DCs, the latter then expressing the maturation marker CD83 
and class I and class II major histocompatibility complexes (MHC). Mature, antigen-presenting DCs migrate to secondary lymphoid tissue where they present antigens to $\mathrm{T}$ cells [8]. While the homing of immature DCs is regulated by chemokine receptors (CCRs) on the DC surface, homing of mature DCs to regional lymph nodes is mediated by CCR7 and CXC-chemokine receptor type 4 (CXCR4) [9-11]. In the secondary lymphoid tissue, $\mathrm{T}$ cells are activated by receiving three signals from mature DCs as follows: (1) mature DCs present an antigen bound to a MHC molecule; (2) T cells then require costimulators such as CD80 or CD86; and (3) cytokines such as IL-12, IL-23, and IL-27 finally are secreted [12]. T cell activation leads to proliferation and differentiation of $\mathrm{T}$ cells into regulatory $\mathrm{T}$ cells $\left(\mathrm{T}_{\text {regs }}\right)$, $\mathrm{T}$ helper cells $\left(\mathrm{T}_{\mathrm{H}}\right)$, or killer T cells. In general, DCs can activate all types of effector $\mathrm{T}$ cells and regulate activation and regulation of immune responses, which are both involved in disease patterns of CVDs.

\section{DCs in Atherosclerosis and Aortocoronary Bypass}

Atherosclerosis is the dominant cause of CVDs leading to myocardial infarction (MI), heart failure (HF), or stroke [13]. The investigation of the underlying pathophysiological mechanisms shows that immune cells such as $\mathrm{T}$ cells, monocytes, and DCs invade the vascular wall stimulated by oxidized LDL, TNF- $\alpha$, and hypoxia $[14,15]$, which are often found in atherosclerotic lesions where they produce proinflammatory cytokines [16]. Both PAMPs and DAMPs can activate DCs [17] which subsequently mature, while further atherogenic factors in the vascular wall such as oxidized low-density lipoprotein (LDL) cholesterol [18], advanced glycation end products (AGE) [19], nicotine [20], insulin [21], and angiotensin II [22] also have the capacity to induce the maturation of DCs. Mature DCs activate T cells and initiate the upregulation of DC licensing factors such as CD40L [17]. These processes contribute to chronic vascular inflammation and form the basis for vascular obliteration.

Several reports on immunohistochemical analyses of carotid specimens raised the suggestion that DCs contribute to plaque destabilization, possibly through activation of $\mathrm{T}$ cells [23-26]. Yilmaz and colleagues analysed mDCs in atherosclerotic plaques in 44 carotid specimens and reported that advanced plaques had higher numbers of mDCs and a higher percentage of mature mDCs than initial lesions [23]. These observations were also confirmed in another patient study $(n=29)$, when unstable compared to stable plaques showed a 1.6-fold increase in both fascin ${ }^{+} \mathrm{mDCs}$ and $\mathrm{S} 100^{+}$ DCs, while a 5.9 -fold increase of mature $\mathrm{CD} 3^{+}$mDCs was observed [26]. However, while these observations could not be detected in pDCs [26], alternative DC markers such as BDCA- 1 and BDCA- 2 have revealed that mDCs and pDCs are indeed recruited to advanced plaques [27].

In addition, the research work of the Weyand laboratory further showed that $53 \%$ of the 30 carotid endarterectomy samples contained $\mathrm{CD} 123^{+}$pDCs, but also CD1lc ${ }^{+}$DC-Sign ${ }^{+}$ fascin $^{+} \mathrm{mDCs}$, which are both located either in the shoulder region of the plaque or at the plaque base. The $\mathrm{mDC} / \mathrm{pDC}$ ratio in the plaques was 2.7 , and further characterization of the pDCs revealed that these cells were the main source of interferon- $\alpha$. The number of pDCs as well as interferon$\alpha$ transcript concentrations strongly correlated with plaque instability in the tissue samples [24, 25]. Further research on the cytokine and chemokine expression in atherosclerotic plaques from coronary artery disease (CAD) patients revealed that the T cell cytokines, interferon- $\gamma$ and TNF- $\alpha$, as well as DC chemokines, CCL19 and CCL21, are increased in patients with ischemic symptoms compared to asymptomatic patients [28].

Beyond DC tissue analyses, circulating DCs hold significant value in patients suffering from atherosclerosis, as supported by CAD patients having increased number of DCs in the atherosclerotic vascular wall concomitant with decreased levels of circulating DCs in the blood [29-33]. While Yilmaz et al. reported a reduction of circulating $\mathrm{mDCs}, \mathrm{pDCs}$, and total DCs in patients with advanced CAD [31] and mDCs in patients with angina pectoris and MI [29], Van Vré et al. found that absolute and relative numbers of circulating pDCs were lowered in $18 \mathrm{CAD}$ patients compared to age- and sexmatched controls [30]. Interestingly, the same group further reported an inverse correlation between mDCs and IL- 6 and C-reactive protein, suggesting that these cytokines may be involved in their regulation [32]. Other factors may also play a role, such as IL-23 and IL-23R [34] and tyrosine kinase 3 ligand (Flt3L) [33], which have also been correlated to pDC levels.

A large clinical study provided further evidence of a strong association between the roles of DCs in CAD, with 290 patients classified as "early CAD," "moderate CAD," "advanced CAD," and "CAD excluded" by coronary angiogram. In summary, the study demonstrated an inverse correlation between the CAD score and $\mathrm{mDCs}, \mathrm{pDCs}$, and total DCs, which were also independent predictors of CAD [31]. Yet noteworthy, patients undergoing percutaneous coronary intervention (PCI) or coronary artery bypass grafting (CABG) had lower total DCs and both DC subsets (mDCs and $\mathrm{pDCs}$ ) compared to no intervention, suggesting that DC levels might be predictive of the targeted therapy after coronary angiogram [31].

Increased levels of DCs are also present in stenotic vein coronary bypass grafts [35]. In comparison to atherosclerosis of coronary arteries, the degeneration of vein grafts proceeds more rapidly [36] and finally leads to graft failure. In general, atherosclerosis develops in almost $50 \%$ of all vein grafts within ten years [37]. Cherian et al. investigated the presence of DCs in vein grafts and found DCs positive for S100 and CDla in the vascular walls of these vessel grafts [35]. A further study on stenotic vein coronary bypass grafts demonstrated that DCs positive for the costimulatory molecule CD40 were clustered within the intima as well as in the media and adventitia [38]. In accordance with the results on human coronary bypass grafts, it has been demonstrated that $\mathrm{T}$ cells were accumulated in the vascular wall of saphenous vein grafts [39]. These data indicate that interactions between DCs and T cells are involved in the rapid development of atherosclerosis and degeneration of vein grafts, which finally promote eventual graft failure. 


\section{Hypertension and DCs}

Hypertension is one of the most common chronic diseases, which promotes atherosclerosis and represents a major risk factor for CVD-related death [40]. A number of studies have suggested that immunological mechanisms, especially the inflammatory responses, are involved in hypertension [4144]. Macrophages and lymphocytes infiltrate the interstitium in angiotensin II-induced hypertension [41], where T cells increase in the adventitia of blood vessels and secrete cytokines such as tumor necrosis factor- $\alpha$ (TNF- $\alpha$ ) and IL-17 as well as NADPH oxidase [43, 45], which then lead to elevated blood pressure. This suggestion is reinforced by observations that immunosuppression causes reduced hypertension-induced end-organ damage while immunodeficiency reduces hypertension $[42,44]$.

While one research arm is related to the investigation of $\mathrm{T}$ cell variations in hypertension, another should represent T cell activating cells, specifically DCs. Indeed, Abbas et al. showed that hypertension activates DCs [34] and also further confirmed that reactive oxygen species (ROS) produced by DCs through phagocyte oxidase caused lipid oxidation, which resulted in accumulation of proteins that were oxidatively modified by highly reactive $\gamma$-ketoaldehydes (isoketals). The isoketal-modified proteins behave like DAMPs and activate DCs, which start to express IL-6, IL-1 $\beta$, and IL-23 and the costimulators CD80 and CD86. The isoketal-pulsed DCs induced $\mathrm{T}$ cell proliferation, particularly of $\mathrm{CD} 8^{+}$and IFN- $\gamma$ and IL-17A, with the latter shown to elevate blood pressure [46]. Thus, one key mechanism of hypertension could be related to an autoimmune component [47], which is supported by evidence that isoketal proteins were traceable in mDCs in hypertensive compared to normotensive controls. Unfortunately, in vivo studies of DCs in hypertension are not well investigated, with only one study on DCs in hypertensive patients [47].

\section{DCs and Heart Failure}

Inflammation and immune responses are processes that can lead to HF such as myocarditis and cardiomyopathy. Myocarditis is an inflammatory heart disease that can be initiated by infectious viruses (e.g., Coxsackie B virus, Parvovirus) or the parasite Trypanosoma cruzi [48]. These pathogens infect cardiomyocytes, which cause direct tissue injury but also initiate immune responses against pathogenic antigens that lead to further tissue damage. In addition, myocarditis has an autoimmune component driven by molecular "mimicry" between microbial and myocardial self-antigens [49]. Molecular mimicry means that specific structures of certain pathogens imitate defined cardiac self-antigens [50]. Subsequently, the $\mathrm{T}$ cell response against such microorganisms includes the expansion of self-reactive $\mathrm{T}$ cells with the potential to attack the myocardium [51]. For example, structural proteins from Chlamydia strains mimic myosin and induce myocarditis after immunizing mice with homologous Chlamydia peptides [52].

A histological study of cardiac samples from autopsied patients with myocarditis $(n=22)$ and from an age- und sex-matched control group $(n=20)$ provided evidence that HLA-DR-positive cardiac DCs proliferate in the acute phase of myocarditis [5]. Cardiac DCs showed typical morphology of DCs with large cellular processes and were in close contact with myocytes, suggesting that cardiac DCs exert a destructive effect on myocytes. This hypothesis is supported by the fact that necrotic lesions were surrounded by infiltrating HLA-DR-positive cells, with dendritic-forming mononuclear cells also in the immediate environment. Similarly, polymorphonuclear giant cells, cardiac DCs, and T cells have also been detected in active inflammatory lesions in chronic patients [5].

MI causes progressive remodeling of myocardial tissue and impairs contractile function, with eventual progression to HF [53]. Immunological and inflammatory processes play an important role in cardiac remodeling after MI [54], with DCs playing a central role in mediating immunological effects following MI by their role in the development of autoimmunological processes and maintenance of peripheral tolerance. For example, MI is characterized by the uptake and presentation of myocardial peptides by DCs resulting in $\mathrm{T}$ cell activation. The infiltration of mature activated CD11c ${ }^{+}$ $\mathrm{CD} 1 \mathrm{~b}^{+}$DCs into the infarcted heart, as well as an association between mature DCs and the deterioration of left ventricle remodeling, has been demonstrated in experimental MI [7, 55]. Furthermore, DCs act as a potent immunoprotective regulator during the post-MI healing process via $\mathrm{DC}$ control of the monocyte/macrophage homeostasis [54], with it being demonstrated early after MI where DCs activate not only regulatory $\mathrm{T}$ cells $\left(\mathrm{T}_{\text {regs }}\right)$, which are purported to prevent tissue-destructive autoimmunity after cardiac injury [56], but also other $\mathrm{T}$ cell subsets such as $\mathrm{CD} 4^{+} \mathrm{T}$ cells [56] and $\mathrm{CD} 4^{+}$ $\mathrm{T}$ cells [57].

The effects on DC populations measured in human tissue are dependent on the type of MI $[58,59]$. For example, a study on infarct tissue in patients with ST-elevation MI (STEMI), where patients with present or absent cardiac rupture were compared, found that $\mathrm{CD} 209^{+} \mathrm{DCs}$ and $\mathrm{CD} 11^{+}$ DC infiltration was higher in patients with cardiac rupture, with a significant positive correlation between $\mathrm{CD} 209^{+}$DCs $\mathrm{CD}_{11 \mathrm{c}^{+}}$DCs and the extent of fibrosis further detected [58]. A more systematically designed study, where STEMI, nonSTEMI (NSTEMI), and CAD $(n=123)$ patients were assessed for tissue-residing and circulating DCs [59], revealed circulating $\mathrm{mDCs}, \mathrm{pDCs}$, and total DCs decreased after acute MI, especially in STEMI patients, with higher DC numbers found in the infarcted myocardium. These results suggest that the lower numbers of circulating DCs after MI may be mediated by DC migration into the myocardium, which is indeed supported by several studies showing a reduction of circulating immature DCs [60], mDCs [61-63], or both, mDCs and pDCs [64] after MI. Further evidence shows that reduced circulating DC numbers return to baseline levels after seven days and do not change for a time period of three months later [64]. Moreover, the $\mathrm{mDC} / \mathrm{pDC}$ ratio seems to be an additional important predictor to distinguish between coronary syndromes, as data has shown that a $\mathrm{mDC} / \mathrm{pDC}$ ratio $\geq 4$ allows patients suffering from acute coronary syndrome to 


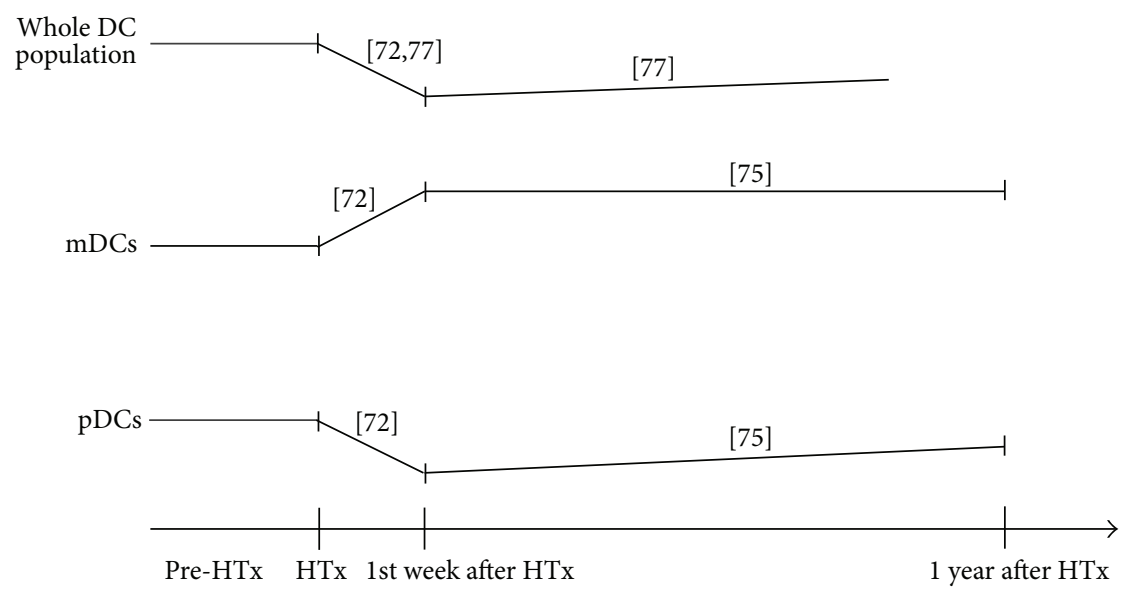

Figure 1: Changes of dendritic cells and their subsets following heart transplantation. Increases and decreases of the whole DC population and the subsets $\mathrm{mDCs}$ and pDCs following heart transplantation were visualized. The appropriate references were added in squared brackets. DCs: dendritic cells; HTx: heart transplantation; mDCs: myeloid dendritic cells; pDCs: plasmacytoid dendritic cells.

be separated compared to those with stable angina pectoris or healthy controls [62].

In contrast, other studies have suggested that autoimmunological processes occur after MI in consequence to defective peripheral tolerance, as autoantibodies against myosin heavy chain, troponins, and $\beta 1$-adrenoreceptors have been found in patients with dilative cardiomyopathy (DCM) or HF [65-69]. Ischemia induces changes not only to DCs but also in DCM, where data shows that chronic DC-driven myocardial inflammation results in ventricular functional impairment with hemodynamic characteristics resembling DCM [70]. Pistulli and coworkers investigated 72 endomyocardial biopsies from patients with diagnosed DCM and found a reduction in both myocardial DCs of all subtypes (mDCs, pDCs, mature DCs, and immature DCs) and maturation markers (fascin, CD11c, CD209, CD83, and CD304), as well as an inverse correlation of DCs with tissue fibrosis. Furthermore, a reduction of $\mathrm{mDCs}$ in DCM hearts in concert with positive testing for cardiotropic viruses has been reported, which raises the hypothesis about a connection between $\mathrm{mDC}$ and myocardial virus clearance [71].

The situation of DCs looks different in whole blood of patients with chronic $\mathrm{HF}$ (CHF) [72], where elevated $\mathrm{mDC}$ and mature DCs levels have been reported while $\mathrm{pDCs}$ were unchanged. It has been hypothesized that the shift of the $\mathrm{mDC} / \mathrm{pDC}$ balance towards mature $\mathrm{mDC}$ may be associated with $\mathrm{T}_{\mathrm{H}} 1$ biased immune responses in later stages of $\mathrm{CHF}$ [72]. A few years after this study was published, Athanassopoulos et al. reported that patients with end-stage CHF of NYHA category III and category IV had comparable levels of circulating DC subsets to NYHA II patients and healthy volunteers [73]. In contrast, Sugi et al. showed that patients with NYHA III and NYHA IV had lower counts of circulating $\mathrm{mDCs}$ and pDCs [74]. After treatment of decompensated HF with optimized oral and intravenous heart insufficiency medication, the reduction of circulating mDCs and $\mathrm{pDCs}$ was restored and increased during the following weeks. Overall, these findings suggest that the role of DCs in the pathophysiology of HF is controversial, with further studies required to clarify the associations between DCs and disease development.

\section{DCs and Heart Transplantation}

The central role of DCs in mediating inflammation and immune tolerance has been demonstrated for MI, myocarditis, DCM, and HF. Aside from these diseases, DCs hold a key role in the immunological processes that are connected to allograft rejection. Inflammatory processes and allograft rejection belong to the major complications after heart transplantation (HTx), whereas immunological tolerance is closely related to a positive outcome following HTx. Clinical studies have focused on monitoring DCs after HTx, with the aim of investigating whether DCs are a valuable marker of immune function status after transplantation [75]. Athanassopoulos et al. examined total peripheral blood $\mathrm{MDC}$ and $\mathrm{pDC}$ subsets expressing CD83 and CCR7 in 16 patients before HTx and one week after HTx compared to 14 healthy controls [72]. A further study of this group investigated DCs and their subsets up to 38 weeks after HTx in $20 \mathrm{HTx}$ patients [76]. Dieterlen et al. investigated DCs and $\mathrm{mDC}$ and $\mathrm{pDC}$ subsets in the first twelve months after HTx in $46 \mathrm{HTx}$ patients [75]. In summary, these studies revealed that patients had higher percentage of DCs before transplantation (Figure 1). Within the first week after HTx, a marked decrease in both the percentage of DCs and that of pDCs was observed but an increase in the percentage of $\mathrm{mDC}$ was observed $[72,76]$, with the number of the whole DC populations increasing continuously during the following months [76]. A more detailed analysis of DC subsets showed that $\mathrm{pDCs}$ increased during the first year after HTx, while mDCs remained constant within that time [75]. In summary, these studies demonstrated that DC incidence and subset distribution differed substantially between recipients before and after HTx as well as in healthy subjects. Thus, it has been stated that DC homeostasis is altered after transplantation (see Figure 1) [77].

Surgery and stress cause a transient increase of peripheral blood DCs $[78,79]$, and therefore the decrease of DCs and 
their subsets in the early posttransplantation period has to be ascribed to the immunosuppressive treatment by antithymocyte globulin, corticosteroids, calcineurin inhibitors, or mycophenolate mofetil $[72,76]$. The different effects and mechanisms of immunosuppressive drugs on DCs are shown in Table 1.

Immunosuppressive drugs keep DC subsets in an immature state, where there is a potent effect not only on maturation but also on the migration characteristics of $\mathrm{mDCs}$ and pDCs [90-92]. These findings are in accordance with a report on circulating DCs, which found lack in the expression of the maturation markers CD83 and CCR7 early after HTx [72]. Furthermore, it has been reported that mycophenolate mofetil influenced phenotype and function during the maturation process, and cyclosporine $\mathrm{A}$ and tacrolimus inhibited DC migration [93]. A direct comparison of cyclosporine A- $(n=$ 14) and tacrolimus-treated $(n=14)$ HTx recipients showed that the percentage of $\mathrm{mDC}$ values was higher and percentage of $\mathrm{pDC}$ values was lower in the cyclosporine A-treated group than in the tacrolimus-treated group. Additionally, monitoring the same study cohort for DC subsets over a period of six months showed that $\mathrm{mDC}$ values only differed at study onset and aligned up to month 6 . In contrast, $\mathrm{pDC}$ values and the $\mathrm{pDC} / \mathrm{mDC}$ ratio differed significantly at all study time points (day 0, month 3 , and month 6) [94]. Barten et al. monitored DCs in 16 HTx patients with regard to the immunosuppressive regimen after conversion of calcineurin inhibitors or sirolimus to everolimus [95]. Regardless of the immunosuppressive regimen, HTx patients had higher percentage of mDCs compared to healthy controls, whereas pDCs were only significantly lower in patients with conversion from calcineurin inhibitors to everolimus. Sirolimus maintenance therapy caused a similar percentage of pDCs compared to controls, with a shift to pDCs in the $\mathrm{pDCs} / \mathrm{mDCs}$ ratio compared to recipients with calcineurin inhibitor therapy. Furthermore, an additional elevated shift in the $\mathrm{pDC} / \mathrm{mDC}$ ratio towards pDCs after conversion from calcineurin inhibitors or sirolimus to everolimus has been observed, which was comparably higher than controls [95].

As mentioned above, DC monitoring is performed to investigate DCs as a marker of immune function status. Thus, studies often correlate DC numbers and acute cellular rejection (ACR). Two different study cohorts have been investigated regarding the influence of rejection episodes on DCs. Firstly, John et al. analysed twenty-eight HTx patients and found that the percentage of pDCs was lower in HTx recipients with rejection compared to HTx recipients without ACR. In contrast, no differences between rejector and nonrejectors have been detected for mDCs [94]. Secondly, a study cohort including twenty-one HTx patients correlated DC subsets with different rejection grades [76, 77]. A negative association of $\mathrm{mDCs}$ but not of $\mathrm{pDCs}$ with the rejection grade determined from endomyocardial biopsies has been found. The number of peripheral blood DCs and the $\mathrm{mDC} / \mathrm{pDC}$ ratio decreased markedly during ACR episodes, and a lower mDC number has been documented even three months after ACR [77]. Furthermore, Athanassopoulos et al. showed that aberrant DC reconstitution is related to adverse clinical outcome after HTx [76].
The central role of DCs in immunological processes led to the development of cellular vaccination strategies aiming to induce transplant tolerance [96]. DCs that are involved in processes leading to tolerance were named "tolerogenic DCs" (tolDCs). tolDCs have immunosuppressive characteristics and exert their function via passive (lack of costimulatory signals) and active (presence of inhibitory signals) tolerance [97]. According to their organism of origin, tolDCs can be classified into "donor-derived tolDCs" and "recipientderived tolDCs." Furthermore, it is possible to generate tolDCs in vitro, for example, from monocytes [98], or to induce tolDCs in vivo.

One possibility for the in vivo induction of tolDCs is extracorporeal photopheresis (ECP) [99]. ECP is an apheresis technique that collects a portion of patients' venous whole blood in a medical device located outside the patients' body (extracorporeal). After separating the blood into its components by centrifugation, the fraction containing white blood cells is treated with the photosensitizing drug methoxsalen and UV-A light and then returned into the patients' circulation. The investigation of DC subsets in HTx patients $(n=25)$ during and after ECP treatment showed that almost $80 \%$ of the treated HTx patients had increased pDCs and regulatory $\mathrm{T}$ cells $\left(\mathrm{T}_{\text {regs }}\right)[100]$. The authors proposed classification criteria based on the individual courses of $\mathrm{pDCs}$ and $\mathrm{T}_{\text {regs }}$ to discriminate between patient specific responses to ECP therapy.

tolDCs induce tolerogenic immune reactions and immunomodulation faster and more frequently than immature DCs [97]. The mechanisms that are involved in immunomodulation are the IL-10- and TGF- $\beta$-driven differentiation of $\mathrm{T}_{\text {regs }}$, the cytokine production that promotes tolDC biology, and the cytokine expression of inhibitory molecules that regulate $\mathrm{T}$ cell responses [97]. Animal models demonstrated that cardiac allograft survival is prolonged by infusion of tolerogenic pDCs in combination with anti-CD40L therapy $[101,102]$. At present, no clinical application of tolDCs is approved or under investigation for HTx. The ONE Study, which is an ongoing multicenter, prospective, and randomized clinical trial, is the first study that evaluates immunomodulatory cellular therapy of ECP on tolDCs in kidney transplantation [103].

Irrespectively of the in vitro generation of tolDCs, different types of tolDCs have been found in humans in vivo [97]. DC-10 cells, a type of mDC expressing IL-10, have been identified by Gregori et al. [104]. This type of tolDC expressed inhibitory molecules (ILT-2, ILT-3, and ILT-4) and the costimulatory surface molecules CD40 and CD86 and trigger tolerogenic effects [104]. Natural tolerogenic pDCs differed in their tolerance-inducing properties compared to tolerogenic mDCs. These differences are caused by the biology of pDCs, which includes a less effective antigen presentation, different maturation characteristics, and expression of costimulatory molecules [105].

\section{Conclusions}

We have reviewed the role and alterations of DCs in CVD and also the current state-of-the-art research. While there remain numerous gaps and contrary findings related to the effects of 


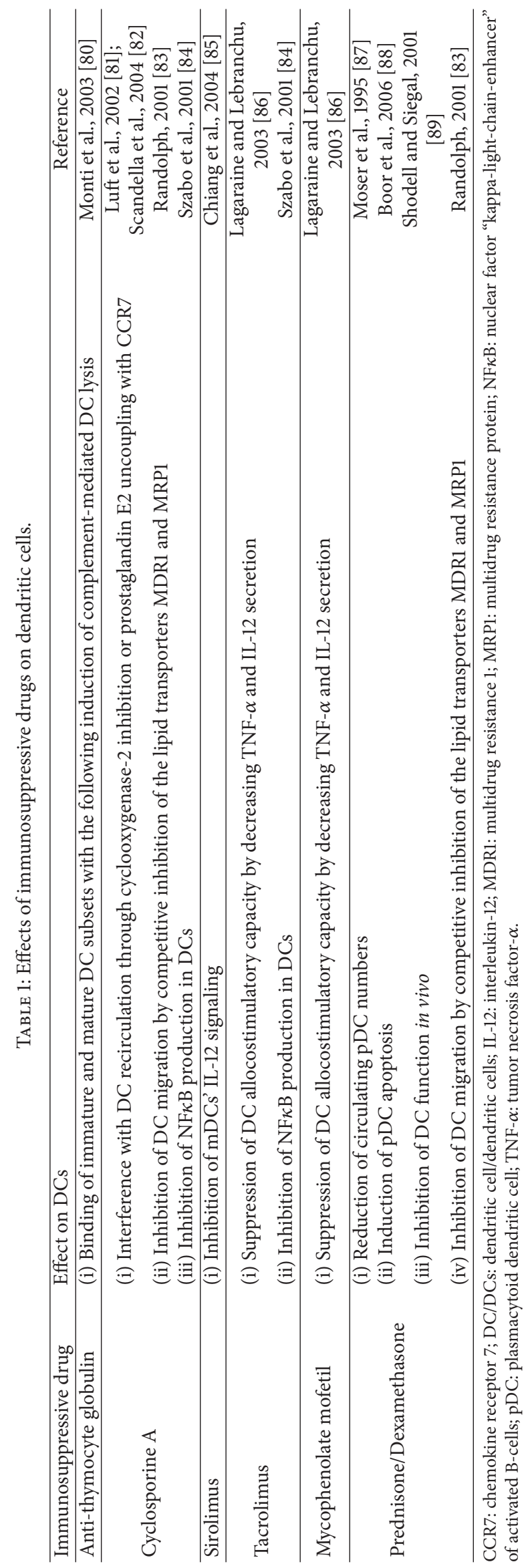




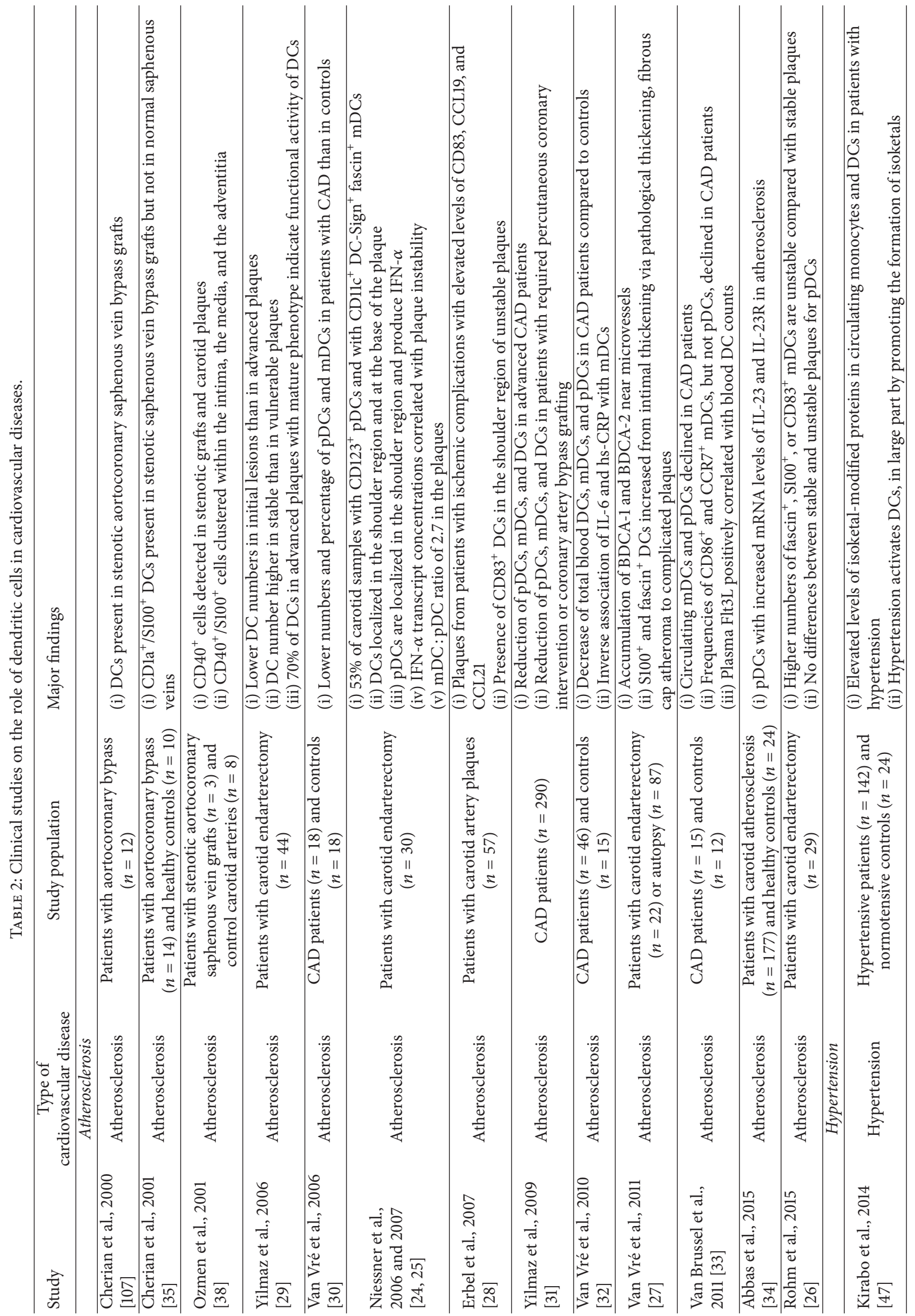




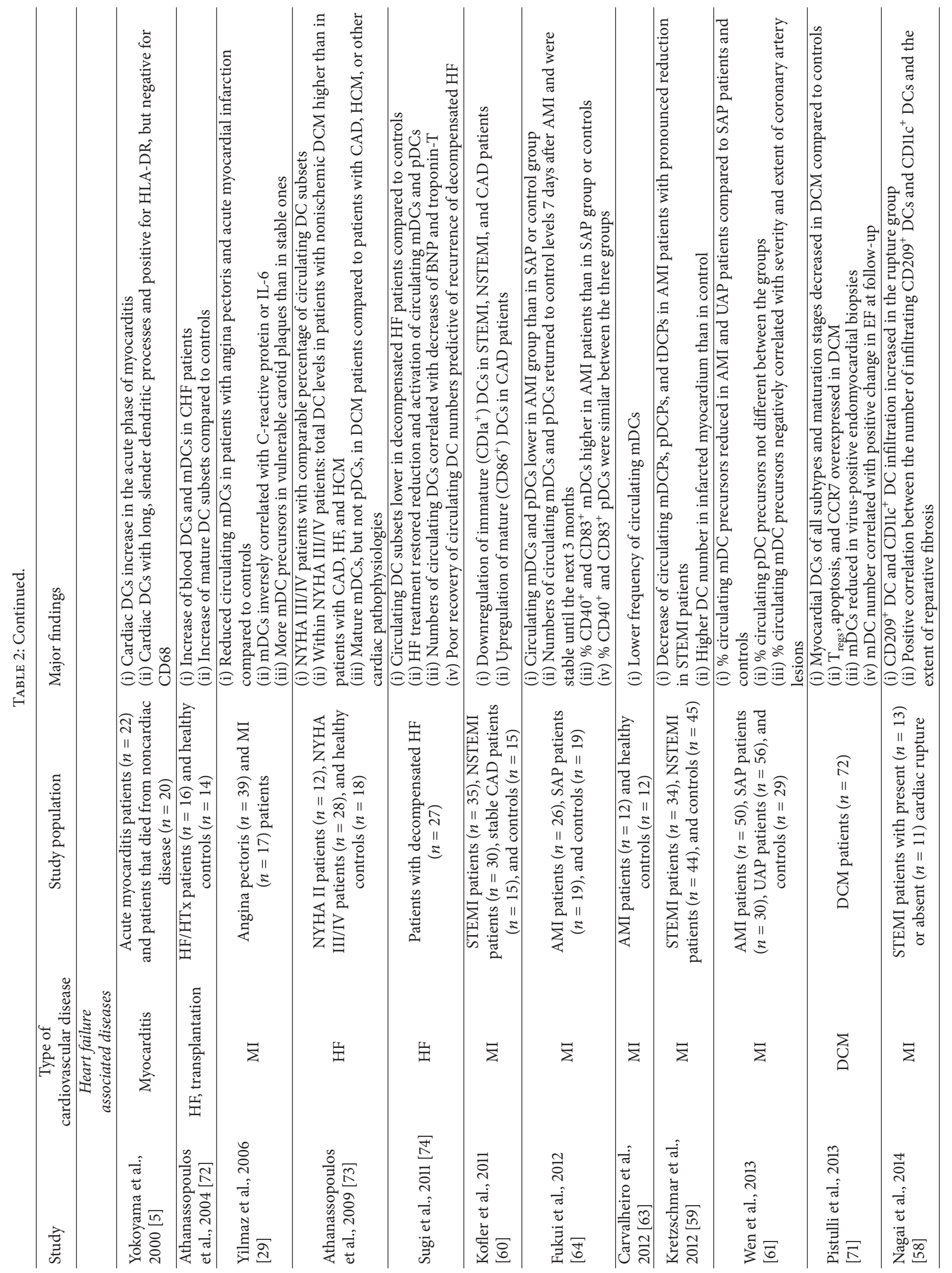




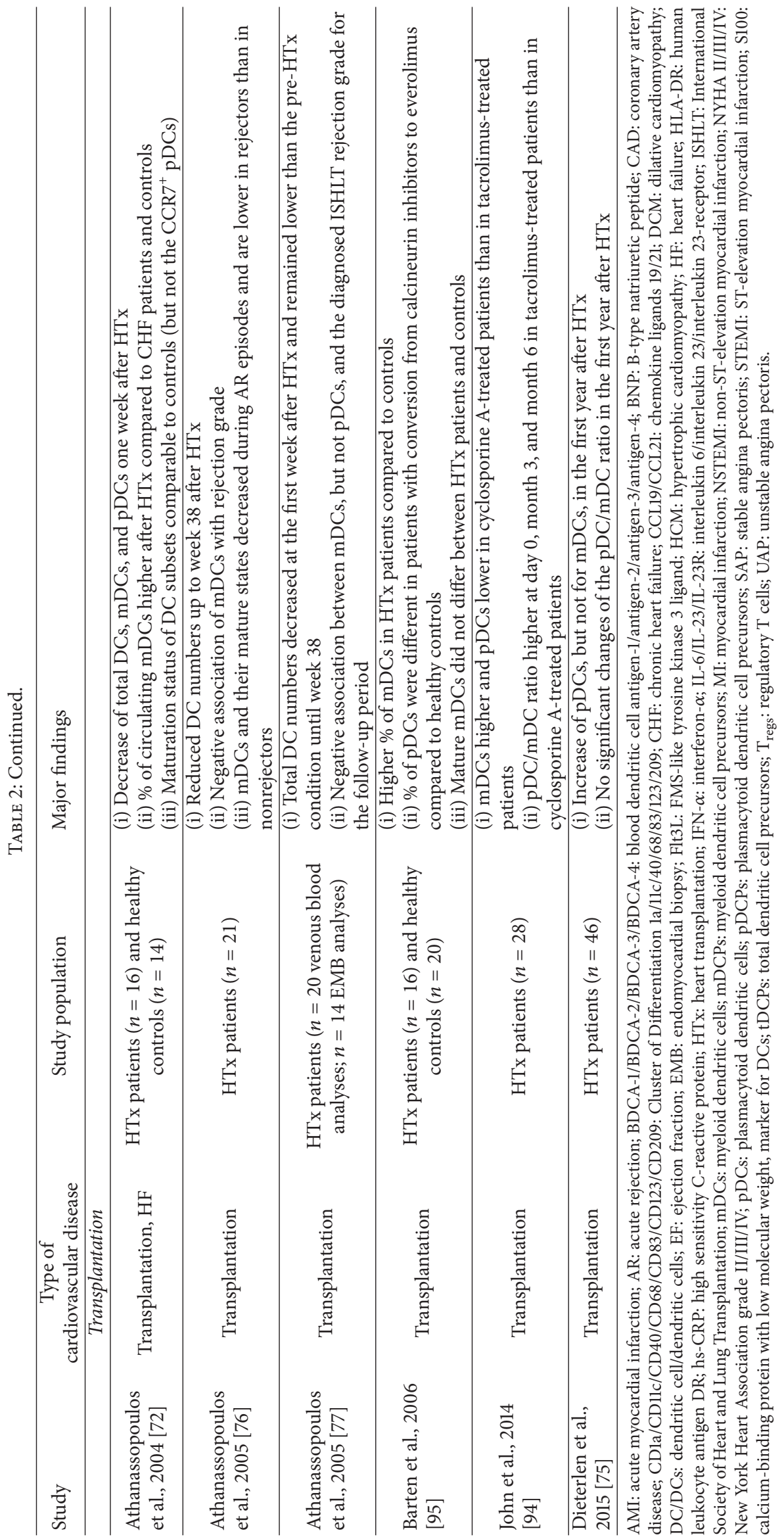


DCs in different CVDs, many observations of human studies are based on circulating measurements despite distinct DCs residing in the tissue that are not detected in analyses of peripheral blood samples. Therefore, analyses of circulating DCs fail to provide information about the processes that are initiated after DC activation or tissue-specific DCs. Such limitations can be closed with further intensive preclinical and clinical research, which should include studies measuring circulating and tissue-residing DCs simultaneously. An interesting aspect, which is yet to be studied in prospective clinical trials, is the role of circulating DCs as immunological markers for CVDs.

While circulating DCs can be analysed by flow cytometry, tissue-residing DCs are measurable by immunohistochemistry or slide-based cytometry [106]. However, it has to be noted that the investigation of tissue-residing DCs requires biopsy material, which may pose additional risks for patients dependent on CVDs. While it is clinical routine to perform endomyocardial biopsies to detect graft rejection after HTx, this is not the case for patients with MI and atherosclerosis.

At present, only few human studies with low patient numbers compared DCs in the tissue with peripheral blood DCs (Table 2). In particular, the role of DCs in hypertension and in diseases leading to HF is still widely unexplored. Furthermore, many studies present conflicting results, which may be related to the different markers used for DC classification, as some study groups favor the classification via the expression of CD11 and others define DC subsets by the markers BDCA1BDCA4, DC-1a, or S100. Thus, a consensus is urgently required on the functional and phenotypical DC classification in order to allow results to become more comparable.

Furthermore, the number of circulating DCs is extremely small with less than $1 \%$ of the leukocytes being DC subsets. Therefore, by using detection methods that are designed to identify very rare cell populations, such as flow cytometry, for example, this problem could be dramatically reduced. However, the establishment of high-throughput methods for clinical diagnostics of DCs is hindered for rare cell populations.

In conclusion, while DCs represent a cell type capable of modulating immunological processes in CVDs, only clinical studies investigating both the circulating and tissue-residing DCs will help further clarify the underlying mechanisms of how these cells exert their immunological effects in humans.

\section{Competing Interests}

The authors declare that there is no conflict of interests regarding the publication of this paper.

\section{References}

[1] S. Mendis, P. Puska, and B. Norrving, Global Atlas on Cardiovascular Disease Prevention and Control, WHO, Geneva, Switzerland, 2011.

[2] D. A. Chistiakov, I. A. Sobenin, A. N. Orekhov, and Y. V. Bobryshev, "Myeloid dendritic cells: development, functions, and role in atherosclerotic inflammation," Immunobiology, vol. 220, pp. 833-844, 2015.
[3] A. Dzionek, A. Fuchs, P. Schmidt et al., "BDCA-2, BDCA-3, and BDCA-4: three markers for distinct subsets of dendritic cells in human peripheral blood," The Journal of Immunology, vol. 165, no. 11, pp. 6037-6046, 2000.

[4] J. Narbutt, A. Lesiak, M. Zak-Prelich et al., "The distribution of peripheral blood dendritic cells assayed by a new panel of antiBDCA monoclonal antibodies in healthy representatives of the Polish population," Cellular and Molecular Biology Letters, vol. 9, no. 3, pp. 497-509, 2004.

[5] H. Yokoyama, S. Kuwao, K. Kohno, K. Suzuki, T. Kameya, and T. Izumi, "Cardiac dendritic cells and acute myocarditis in the human heart," Japanese Circulation Journal, vol. 64, no. 1, pp. 57-64, 2000.

[6] D. N. J. Hart and J. W. Fabre, "Demonstration and characterization of Ia-positive dendritic cells in the interstitial connective tissue of rat heart and other tissues, but not brain," The Journal of Experimental Medicine, vol. 154, no. 2, pp. 347-361, 1981.

[7] J. Zhang, Z.-X. Yu, S. Fujita, M. L. Yamaguchi, and V. J. Ferrans, "Interstitial dendritic cells of the rat heart. Quantitative and ultrastructural changes in experimental myocardial infarction," Circulation, vol. 87, no. 3, pp. 909-920, 1993.

[8] J. Banchereau, F. Briere, C. Caux et al., "Immunobiology of dendritic cells," Annual Review of Immunology, vol. 18, pp. 767$811,2000$.

[9] F. Sallusto, B. Palermo, D. Lenig et al., "Distinct patterns and kinetics of chemokine production regulate dendritic cell function," European Journal of Immunology, vol. 29, no. 5, pp. 1617-1625, 1999.

[10] C. Delgado-Martín, C. Escribano, J. L. Pablos, L. Riol-Blanco, and J. L. Rodríguez-Fernández, "Chemokine CXCL12 uses CXCR4 and a signaling core formed by bifunctional akt, Extracellular Signal-regulated Kinase (ERK)1/2, and Mammalian Target of Rapamycin Complex 1 (mTORC1) proteins to control chemotaxis and survival simultaneously in mature dendritic cells," The Journal of Biological Chemistry, vol. 286, no. 43, pp. 37222-37236, 2011.

[11] G. J. Randolph, J. Ochando, and S. Partida-Sánchez, "Migration of dendritic cell subsets and their precursors," Annual Review of Immunology, vol. 26, pp. 293-316, 2008.

[12] J. M. Curtsinger and M. F. Mescher, "Inflammatory cytokines as a third signal for $\mathrm{T}$ cell activation," Current Opinion in Immunology, vol. 22, no. 3, pp. 333-340, 2010.

[13] J. Frostegård, "Immunity, atherosclerosis and cardiovascular disease," BMC Medicine, vol. 11, article 117, 2013.

[14] M. Weis, C. L. Schlichting, E. G. Engleman, and J. P. Cooke, "Endothelial determinants of dendritic cell adhesion and migration: new implications for vascular diseases," Arteriosclerosis, Thrombosis, and Vascular Biology, vol. 22, no. 11, pp. 1817$1823,2002$.

[15] G. K. Hansson, "Inflammation, atherosclerosis, and coronary artery disease," The New England Journal of Medicine, vol. 352, no. 16, pp. 1626-1695, 2005.

[16] J. Frostegård, A.-K. Ulfgren, P. Nyberg et al., "Cytokine expression in advanced human atherosclerotic plaques: dominance of pro-inflammatory (Th1) and macrophage-stimulating cytokines," Atherosclerosis, vol. 145, no. 1, pp. 33-43, 1999.

[17] L. S. Deluca and J. L. Gommerman, "Fine-tuning of dendritic cell biology by the TNF superfamily," Nature Reviews Immunology, vol. 12, no. 5, pp. 339-351, 2012.

[18] C. J. J. Alderman, P. R. Bunyard, B. M. Chain, J. C. Foreman, D. S. Leake, and D. R. Katz, "Effects of oxidised low density 
lipoprotein on dendritic cells: a possible immunoregulatory component of the atherogenic micro-environment?" Cardiovascular Research, vol. 55, no. 4, pp. 806-819, 2002.

[19] J. Ge, Q. Jia, C. Liang et al., "Advanced glycosylation end products might promote atherosclerosis through inducing the immune maturation of dendritic cells," Arteriosclerosis, Thrombosis, and Vascular Biology, vol. 25, no. 10, pp. 2157-2163, 2005.

[20] A. Aicher, C. Heeschen, M. Mohaupt, J. P. Cooke, A. M. Zeiher, and S. Dimmeler, "Nicotine strongly activates dendritic cellmediated adaptive immunity: potential role for progression of atherosclerotic lesions," Circulation, vol. 107, no. 4, pp. 604-611, 2003.

[21] H. Lu, D. Huang, K. Yao et al., "Insulin enhances dendritic cell maturation and scavenger receptor-mediated uptake of oxidised low-density lipoprotein," Journal of Diabetes and Its Complications, vol. 29, no. 4, pp. 465-471, 2015.

[22] W. Nie, H. Yan, S. Li, W. Zhu, F. Fan, and J. Zhu, "Angiotensin II promotes atherogenesis through upregulating the expression of connexin 43 in dendritic cells," Cellular and Molecular Biology (Noisy-le-Grand), vol. 61, no. 3, pp. 96-101, 2015.

[23] A. Yilmaz, M. Lochno, F. Traeg et al., "Emergence of dendritic cells in rupture-prone regions of vulnerable carotid plaques," Atherosclerosis, vol. 176, no. 1, pp. 101-110, 2004.

[24] A. Niessner, K. Sato, E. L. Chaikof, I. Colmegna, J. J. Goronzy, and C. M. Weyand, "Pathogen-sensing plasmacytoid dendritic cells stimulate cytotoxic T-cell function in the atherosclerotic plaque through interferon- $\alpha$," Circulation, vol. 114, no. 23, pp. 2482-2489, 2006.

[25] A. Niessner, M. S. Shin, O. Pryshchep, J. J. Goronzy, E. L. Chaikof, and C. M. Weyand, "Synergistic proinflammatory effects of the antiviral cytokine interferon- $\alpha$ and toll-like receptor 4 ligands in the atherosclerotic plaque," Circulation, vol. 116, no. 18, pp. 2043-2052, 2007.

[26] I. Rohm, Y. Atiskova, S. Drobnik et al., "Decreased regulatory $\mathrm{T}$ cells in vulnerable atherosclerotic lesions: imbalance between pro- and anti-inflammatory cells in atherosclerosis," Mediators of Inflammation, vol. 2015, Article ID 364710, 13 pages, 2015.

[27] E. A. Van Vré, J. M. Bosmans, I. Van Brussel et al., "Immunohistochemical characterisation of dendritic cells in human atherosclerotic lesions: possible pitfalls," Pathology, vol. 43, no. 3, pp. 239-247, 2011.

[28] C. Erbel, K. Sato, F. B. Meyer et al., "Functional profile of activated dendritic cells in unstable atherosclerotic plaque," Basic Research in Cardiology, vol. 102, no. 2, pp. 123-132, 2007.

[29] A. Yilmaz, J. Weber, I. Cicha et al., "Decrease in circulating myeloid dendritic cell precursors in coronary artery disease," Journal of the American College of Cardiology, vol. 48, no. 1, pp. 70-80, 2006.

[30] E. A. Van Vré, V. Y. Hoymans, H. Bult et al., "Decreased number of circulating plasmacytoid dendritic cells in patients with atherosclerotic coronary artery disease," Coronary Artery Disease, vol. 17, no. 3, pp. 243-248, 2006.

[31] A. Yilmaz, T. Schaller, I. Cicha et al., "Predictive value of the decrease in circulating dendritic cell precursors in stable coronary artery disease," Clinical Science, vol. 116, no. 4, pp. 353363, 2009.

[32] E. A. Van Vré, I. Van Brussel, K. O. de Beeck et al., "Changes in blood dendritic cell counts in relation to type of coronary artery disease and brachial endothelial cell function," Coronary Artery Disease, vol. 21, no. 2, pp. 87-96, 2010.

[33] I. Van Brussel, E. A. Van Vré, G. R. Y. De Meyer, C. J. Vrints, J. M. Bosmans, and H. Bult, "Decreased numbers of peripheral blood dendritic cells in patients with coronary artery disease are associated with diminished plasma Flt3 ligand levels and impaired plasmacytoid dendritic cell function," Clinical Science, vol. 120, no. 9, pp. 415-426, 2011.

[34] A. Abbas, I. Gregersen, S. Holm et al., "Interleukin 23 levels are increased in carotid atherosclerosis: possible role for the interleukin 23/interleukin 17 axis," Stroke, vol. 46, pp. 793-799, 2015.

[35] S. M. Cherian, Y. V. Bobryshev, H. Liang et al., "Immunohistochemical and ultrastructural evidence that dendritic cells infiltrate stenotic aortocoronary saphenous vein bypass grafts," Cardiovascular Surgery, vol. 9, no. 2, pp. 194-200, 2001.

[36] B. H. Bulkley and G. M. Hutchins, "Accelerated 'atherosclerosis'. A morphologic study of 97 saphenous vein coronary artery bypass grafts," Circulation, vol. 55, no. 1, pp. 163-169, 1977.

[37] L. Campeau, M. Enjalbert, J. Lespérance, C. Vaislic, C. M. Grondin, and M. G. Bourassa, "Atherosclerosis and late closure of aortocoronary saphenous vein grafts: sequential angiographic studies at 2 weeks, 1 year, 5 to 7 years, and 10 to 12 years after surgery," Circulation, vol. 68, no. 3, part 2, pp. II1-II7, 1983.

[38] J. Ozmen, Y. V. Bobryshev, and R. S. A. Lord, "CD40 costimulatory molecule expression by dendritic cells in primary atherosclerotic lesions in carotid arteries and in stenotic saphenous vein coronary artery grafts," Cardiovascular Surgery, vol. 9, no. 4, pp. 329-333, 2001.

[39] G. Wick, M. Romen, A. Amberger et al., "Atherosclerosis, autoimmunity, and vascular-associated lymphoid tissue," The FASEB Journal, vol. 11, no. 13, pp. 1199-1207, 1997.

[40] P. S. Yusuf, S. Hawken, S. Ônpuu et al., "Effect of potentially modifiable risk factors associated with myocardial infarction in 52 countries (the INTERHEART study): case-control study," The Lancet, vol. 364, no. 9438, pp. 937-952, 2004.

[41] D. N. Muller, E. Shagdarsuren, J.-K. Park et al., "Immunosuppressive treatment protects against angiotensin II-induced renal damage," The American Journal of Pathology, vol. 161, no. 5, pp. 1679-1693, 2002.

[42] C. Nataraj, M. I. Oliverio, R. B. Mannon et al., "Angiotensin II regulates cellular immune responses through a calcineurindependent pathway," The Journal of Clinical Investigation, vol. 104, no. 12, pp. 1693-1701, 1999.

[43] M. S. Madhur, H. E. Lob, L. A. McCann et al., "Interleukin 17 promotes angiotensin II-induced hypertension and vascular dysfunction," Hypertension, vol. 55, no. 2, pp. 500-507, 2010.

[44] S. D. Crowley, Y.-S. Song, E. E. Lin, R. Griffiths, H.-S. Kim, and P. Ruiz, "Lymphocyte responses exacerbate angiotensin IIdependent hypertension," The American Journal of PhysiologyRegulatory Integrative and Comparative Physiology, vol. 298, no. 4, pp. R1089-R1097, 2010.

[45] T. J. Guzik, N. E. Hoch, K. A. Brown et al., "Role of the T cell in the genesis of angiotensin II-induced hypertension and vascular dysfunction," Journal of Experimental Medicine, vol. 204, no. 10, pp. 2449-2460, 2007.

[46] H. Nguyen, V. L. Chiasson, P. Chatterjee, S. E. Kopriva, K. J. Young, and B. M. Mitchell, "Interleukin-17 causes Rhokinase-mediated endothelial dysfunction and hypertension," Cardiovascular Research, vol. 97, no. 4, pp. 696-704, 2013.

[47] A. Kirabo, V. Fontana, A. P. C. de Faria et al., "DC isoketalmodified proteins activate T cells and promote hypertension," The Journal of Clinical Investigation, vol. 124, no. 10, pp. 46424656, 2014.

[48] S. Sagar, P. P. Liu, and L. T. Cooper Jr., "Myocarditis," The Lancet, vol. 379, no. 9817, pp. 738-747, 2012. 
[49] G. K. Griffin and A. H. Lichtman, "Two sides to every proinflammatory coin: new insights into the role of dendritic cells in the regulation of T-cell driven autoimmune myocarditis," Circulation, vol. 127, no. 23, pp. 2257-2260, 2013.

[50] R. R. Marty and U. Eriksson, "Dendritic cells and autoimmune heart failure," International Journal of Cardiology, vol. 112, no. 1, pp. 34-39, 2006.

[51] N. R. Rose, "Infection, mimics, and autoimmune disease," The Journal of Clinical Investigation, vol. 107, no. 8, pp. 943-944, 2001.

[52] K. Bachmaier, N. Nikolaus, L. M. de la Maza, P. Sukumar, A. Hessel, and J. M. Penninger, "Chlamydia infections and heart disease linked through antigenic mimicry," Science, vol. 283, no. 5406, pp. 1335-1339, 1999.

[53] U. Hofmann and S. Frantz, "Role of lymphocytes in myocardial injury, healing, and remodeling after myocardial infarction," Circulation Research, vol. 116, no. 2, pp. 354-367, 2015.

[54] A. Anzai, T. Anzai, S. Nagai et al., "Regulatory role of dendritic cells in postinfarction healing and left ventricular remodeling," Circulation, vol. 125, no. 10, pp. 1234-1245, 2012.

[55] K. Naito, T. Anzai, Y. Sugano et al., "Differential effects of GMCSF and G-CSF on infiltration of dendritic cells during early left ventricular remodeling after myocardial infarction," Journal of Immunology, vol. 181, no. 8, pp. 5691-5701, 2008.

[56] U. Hofmann, N. Beyersdorf, J. Weirather et al., "Activation of $\mathrm{CD}^{+} \mathrm{T}$ lymphocytes improves wound healing and survival after experimental myocardial infarction in mice," Circulation, vol. 125, no. 13, pp. 1652-1663, 2012.

[57] H. Liu, W. Gao, J. Yuan et al., "Exosomes derived from dendritic cells improve cardiac function via activation of $\mathrm{CD} 4^{+} \mathrm{T}$ lymphocytes after myocardial infarction," Journal of Molecular and Cellular Cardiology, vol. 91, pp. 123-133, 2016.

[58] T. Nagai, S. Honda, Y. Sugano et al., "Decreased myocardial dendritic cells is associated with impaired reparative fibrosis and development of cardiac rupture after myocardial infarction in humans," Journal of the American Heart Association, vol. 3, Article ID e000839, 2014.

[59] D. Kretzschmar, S. Betge, A. Windisch et al., "Recruitment of circulating dendritic cell precursors into the infarcted myocardium and pro-inflammatory response in acute myocardial infarction," Clinical Science, vol. 123, no. 6, pp. 387-398, 2012.

[60] S. Kofler, Z. Sisic, N. Shvets, P. Lohse, and M. Weis, "Expression of circulatory dendritic cells and regulatory T-cells in patients with different subsets of coronary artery disease," Journal of Cardiovascular Pharmacology, vol. 57, no. 5, pp. 542-549, 2011.

[61] J. Wen, Y. Wen, L. Zhiliang et al., "A decrease in the percentage of circulating $\mathrm{mDC}$ precursors in patients with coronary heart disease: a relation to the severity and extent of coronary artery lesions?" Heart and Vessels, vol. 28, no. 2, pp. 135-142, 2013.

[62] T. Fukunaga, H. Soejima, A. Irie et al., "High ratio of myeloid dendritic cells to plasmacytoid dendritic cells in blood of patients with acute coronary syndrome," Circulation Journal, vol. 73, no. 10, pp. 1914-1919, 2009.

[63] T. Carvalheiro, I. Velada, A. Valado et al., "Phenotypic and functional alterations on inflammatory peripheral blood cells after acute myocardial infarction," Journal of Cardiovascular Translational Research, vol. 5, no. 3, pp. 309-320, 2012.

[64] D. Fukui, H. Yasukawa, Y. Sugi et al., "Transient reduction and activation of circulating dendritic cells in patients with acute myocardial infarction," International Journal of Cardiology, vol. 160, no. 3, pp. 216-219, 2012.
[65] U. Eriksson, R. Ricci, L. Hunziker et al., "Dendritic cell-induced autoimmune heart failure requires cooperation between adaptive and innate immunity," Nature Medicine, vol. 9, no. 12, pp. 1484-1490, 2003.

[66] A. L. P. Caforio, M. Grazzini, J. M. Mann et al., "Identification of $\alpha$ - and $\beta$-cardiac myosin heavy chain isoforms as major autoantigens in dilated cardiomyopathy," Circulation, vol. 85, no. 5, pp. 1734-1742, 1992.

[67] Z. Kaya, C. Leib, and H. A. Katus, "Autoantibodies in heart failure and cardiac dysfunction," Circulation Research, vol. 110, no. 1, pp. 145-158, 2012.

[68] F. Leuschner, J. Li, S. Göser et al., "Absence of auto-antibodies against cardiac troponin I predicts improvement of left ventricular function after acute myocardial infarction," European Heart Journal, vol. 29, no. 16, pp. 1949-1955, 2008.

[69] V. Boivin-Jahns, A. Schlipp, S. Hartmann et al., "Antibodies to cardiac receptors," Herz, vol. 37, no. 8, pp. 843-848, 2012.

[70] M. Afanasyeva, D. Georgakopoulos, D. F. Belardi et al., "Quantitative analysis of myocardial inflammation by flow cytometry in murine autoimmune myocarditis: correlation with cardiac function," The American Journal of Pathology, vol. 164, no. 3, pp. 807-815, 2004.

[71] R. Pistulli, S. König, S. Drobnik et al., "Decrease in dendritic cells in endomyocardial biopsies of human dilated cardiomyopathy," European Journal of Heart Failure, vol. 15, no. 9, pp. 974985, 2013.

[72] P. Athanassopoulos, L. M. B. Vaessen, A. P. W. M. Maat, A. H. M. M. Balk, W. Weimar, and A. J. J. C. Bogers, "Peripheral blood dendritic cells in human end-stage heart failure and the early post-transplant period: evidence for systemic Thl immune responses," European Journal of Cardio-Thoracic Surgery, vol. 25, no. 4, pp. 619-626, 2004.

[73] P. Athanassopoulos, A. H. M. M. Balk, L. M. B. Vaessen et al., "Blood dendritic cell levels and phenotypic characteristics in relation to etiology of end-stage heart failure: implications for dilated cardiomyopathy," International Journal of Cardiology, vol. 131, no. 2, pp. 246-256, 2009.

[74] Y. Sugi, H. Yasukawa, H. Kai et al., "Reduction and activation of circulating dendritic cells in patients with decompensated heart failure," International Journal of Cardiology, vol. 147, no. 2, pp. 258-264, 2011.

[75] M. Dieterlen, F. W. Mohr, H. Reichenspurner, and M. J. Barten, "Clinical value of flow cytometric assessment of dendritic cell subsets in peripheral blood after solid organ transplantation," Cytometry A, vol. 87, no. 5, pp. 377-379, 2015.

[76] P. Athanassopoulos, L. M. B. Vaessen, A. H. M. M. Balk et al., "Impaired circulating dendritic cell reconstitution identifies rejecting recipients after clinical heart transplantation independent of rejection therapy," European Journal of Cardio-Thoracic Surgery, vol. 27, no. 5, pp. 783-789, 2005.

[77] P. Athanassopoulos, L. M. B. Vaessen, A. P. W. M. Maat et al., "Preferential depletion of blood myeloid dendritic cells during acute cardiac allograft rejection under controlled immunosuppression," American Journal of Transplantation, vol. 5, no. 4, pp. 810-820, 2005.

[78] C. S. K. Ho, J. A. López, S. Vuckovic, C. M. Pyke, R. L. Hockey, and D. N. J. Hart, "Surgical and physical stress increases circulating blood dendritic cell counts independently of monocyte counts," Blood, vol. 98, no. 1, pp. 140-145, 2001. 
[79] F. S. Dhabhar and B. S. McEwen, "Enhancing versus suppressive effects of stress hormones on skin immune function," Proceedings of the National Academy of Sciences of the United States of America, vol. 96, no. 3, pp. 1059-1064, 1999.

[80] P. Monti, P. Allavena, V. Di Carlo, and L. Piemonti, "Effects of anti-lymphocytes and anti-thymocytes globulin on human dendritic cells," International Immunopharmacology, vol. 3, no. 2, pp. 189-196, 2003.

[81] T. Luft, M. Jefford, P. Luetjens et al., "Functionally distinct dendritic cell (DC) populations induced by physiologic stimuli: prostaglandin $\mathrm{E}_{2}$ regulates the migratory capacity of specific DC subsets," Blood, vol. 100, no. 4, pp. 1362-1372, 2002.

[82] E. Scandella, Y. Men, D. F. Legler et al., “CCL19/CCL21-triggered signal transduction and migration of dendritic cells requires prostaglandin E2," Blood, vol. 103, no. 5, pp. 1595-1601, 2004.

[83] G. J. Randolph, "Dendritic cell migration to lymph nodes: cytokines, chemokines, and lipid mediators," Seminars in Immunology, vol. 13, no. 5, pp. 267-274, 2001.

[84] G. Szabo, C. Gavala, and P. Mandrekar, "Tacrolimus and cyclosporine A inhibit allostimulatory capacity and cytokine production of human myeloid dendritic cells," Journal of Investigative Medicine, vol. 49, no. 5, pp. 442-449, 2001.

[85] P.-H. Chiang, L. Wang, C. A. Bonham et al., "Mechanistic insights into impaired dendritic cell function by rapamycin: inhibition of Jak2/Stat4 signaling pathway," The Journal of Immunology, vol. 172, no. 3, pp. 1355-1363, 2004.

[86] C. Lagaraine and Y. Lebranchu, "Effects of immunosuppressive drugs on dendritic cells and tolerance induction," Transplantation, vol. 75, no. 9, pp. 37S-42S, 2003.

[87] M. Moser, T. De Smedt, T. Sornasse et al., "Glucocorticoids down-regulate dendritic cell function in vitro and in vivo," European Journal of Immunology, vol. 25, no. 10, pp. 2818-2824, 1995.

[88] P. P. C. Boor, H. J. Metselaar, S. Mancham, H. W. Tilanus, J. G. Kusters, and J. Kwekkeboom, "Prednisolone suppresses the function and promotes apoptosis of plasmacytoid dendritic cells," American Journal of Transplantation, vol. 6, no. 10, pp. 2332-2341, 2006

[89] M. Shodell and F. P. Siegal, "Corticosteroids depress IFN$\alpha$-producing plasmacytoid dendritic cells in human blood," Journal of Allergy and Clinical Immunology, vol. 108, no. 3, pp. 446-448, 2001.

[90] G. Raimondi and A. W. Thomson, "Dendritic cells, tolerance and therapy of organ allograft rejection," Contributions to Nephrology, vol. 146, pp. 105-120, 2005.

[91] M. Abe and A. W. Thomson, "Influence of immunosuppressive drugs on dendritic cells," Transplant Immunology, vol. 11, no. 34, pp. 357-365, 2003.

[92] K. L. Womer, R. Peng, P. R. Patton et al., "The effects of renal transplantation on peripheral blood dendritic cells," Clinical Transplantation, vol. 19, no. 5, pp. 659-667, 2005.

[93] V. Daniel, "Dendritic cells and immunosuppression after organ transplantation," LaboratoriumsMedizin, vol. 32, no. 3, pp. 131139, 2008.

[94] K. John, M.-T. Dieterlen, A. Tarnok et al., "Role of dendritic cells in the context of acute cellular rejection: comparison between tacrolimus- or cyclosporine A-treated heart transplanted recipients," Cytometry B-Clinical Cytometry, vol. 86, no. 5, pp. 362367, 2014.
[95] M. J. Barten, J. Garbade, H. B. Bittner et al., "Affects of immuno suppression on circulating dendritic cells: an adjunct to therapeutic drug monitoring after heart transplantation," International Immunopharmacology, vol. 6, no. 13-14, pp. 2011-2017, 2006.

[96] C. van Kooten, G. Lombardi, K. A. Gelderman et al., "Dendritic cells as a tool to induce transplantation tolerance: obstacles and opportunities," Transplantation, vol. 91, no. 1, pp. 2-7, 2011.

[97] U. Švajger and P. Rožman, “Tolerogenic dendritic cells: molecular and cellular mechanisms in transplantation," Journal of Leukocyte Biology, vol. 95, no. 1, pp. 53-69, 2014.

[98] A. Moreau, E. Varey, L. Bouchet-Delbos, and M. C. Cuturi, "Cell therapy using tolerogenic dendritic cells in transplantation," Transplantation Research, vol. 1, no. 1, article 13, 2012.

[99] A. Lamioni, F. Parisi, G. Isacchi et al., "The immunological effects of extracorporeal photopheresis unraveled: induction of tolerogenic dendritic cells in vitro and regulatory $\mathrm{T}$ cells in vivo," Transplantation, vol. 79, no. 7, pp. 846-850, 2005.

[100] M.-T. Dieterlen, H. B. Bittner, A. Pierzchalski, S. Dhein, F. W. Mohr, and M. J. Barten, "Immunological monitoring of extracorporeal photopheresis after heart transplantation," Clinical and Experimental Immunology, vol. 176, no. 1, pp. 120-128, 2014.

[101] M. Abe, Z. Wang, A. de Creus, and A. W. Thomson, "Plasmacytoid dendritic cell precursors induce allogeneic T-cell hyporesponsiveness and prolong heart graft survival," American Journal of Transplantation, vol. 5, no. 8, pp. 1808-1819, 2005.

[102] P. Björck, P. T. H. Coates, Z. Wang, F. J. Duncan, and A. W. Thomson, "Promotion of long-term heart allograft survival by combination of mobilized donor plasmacytoid dendritic cells and anti-CD154 monoclonal antibody," Journal of Heart and Lung Transplantation, vol. 24, no. 8, pp. 1118-1120, 2005.

[103] H. Li and B. Shi, "Tolerogenic dendritic cells and their applications in transplantation," Cellular and Molecular Immunology, vol. 12, no. 1, pp. 24-30, 2015.

[104] S. Gregori, D. Tomasoni, V. Pacciani et al., "Differentiation of type $1 \mathrm{~T}$ regulatory cells (Tr1) by tolerogenic DC-10 requires the IL-10-dependent ILT4/HLA-G pathway," Blood, vol. 116, no. 6, pp. 935-944, 2010.

[105] L. J. Young, N. S. Wilson, P. Schnorrer et al., "Differential MHC class II synthesis and ubiquitination confers distinct antigenpresenting properties on conventional and plasmacytoid dendritic cells," Nature Immunology, vol. 9, no. 11, pp. 1244-1252, 2008.

[106] O. H. Gerstner, W. Laffers, and A. Tárnok, "Clinical applications of slide-based cytometry-an update," Journal of Biophotonics, vol. 2, no. 8-9, pp. 463-469, 2009.

[107] S. M. Cherian, Y. V. Bobryshev, S. J. Inder, A. Y. Wang, R. S. A. Lord, and A. E. Farnsworth, "Dendritic cells in aortocoronary saphenous vein bypass grafts," Heart Lung and Circulation, vol. 9, no. 1, pp. 39-42, 2000. 


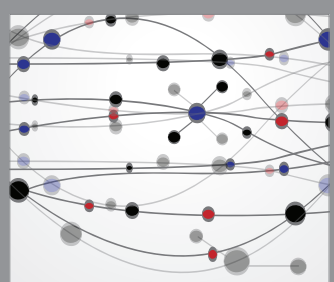

The Scientific World Journal
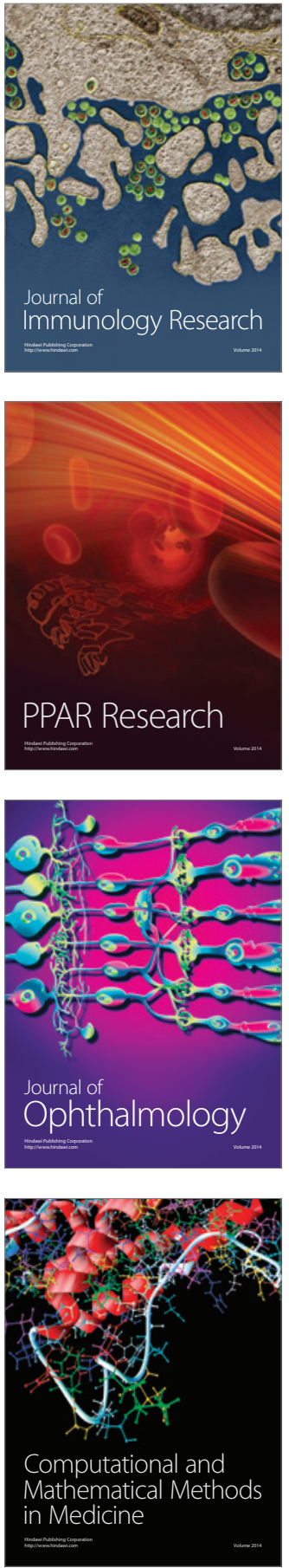

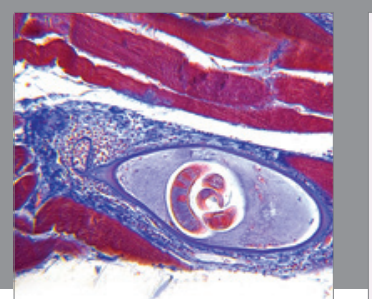

Gastroenterology Research and Practice

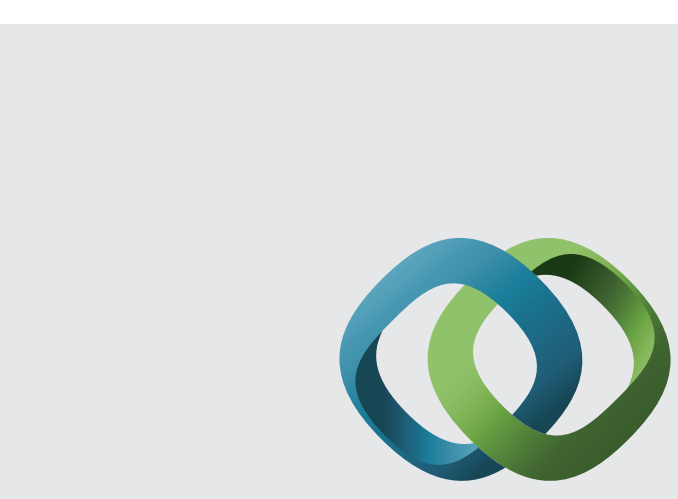

\section{Hindawi}

Submit your manuscripts at

http://www.hindawi.com
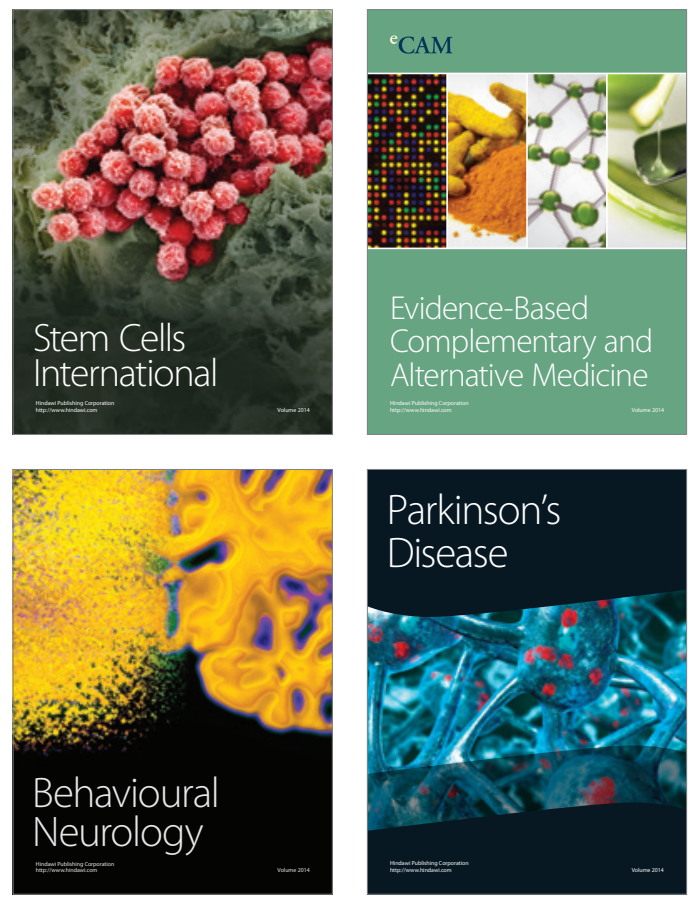
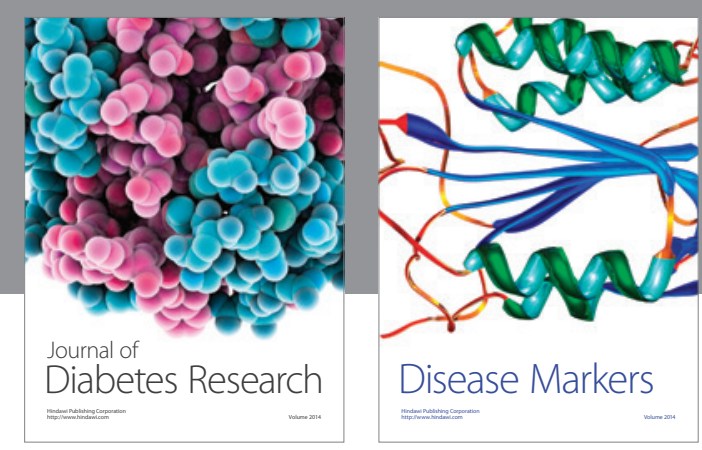

Disease Markers
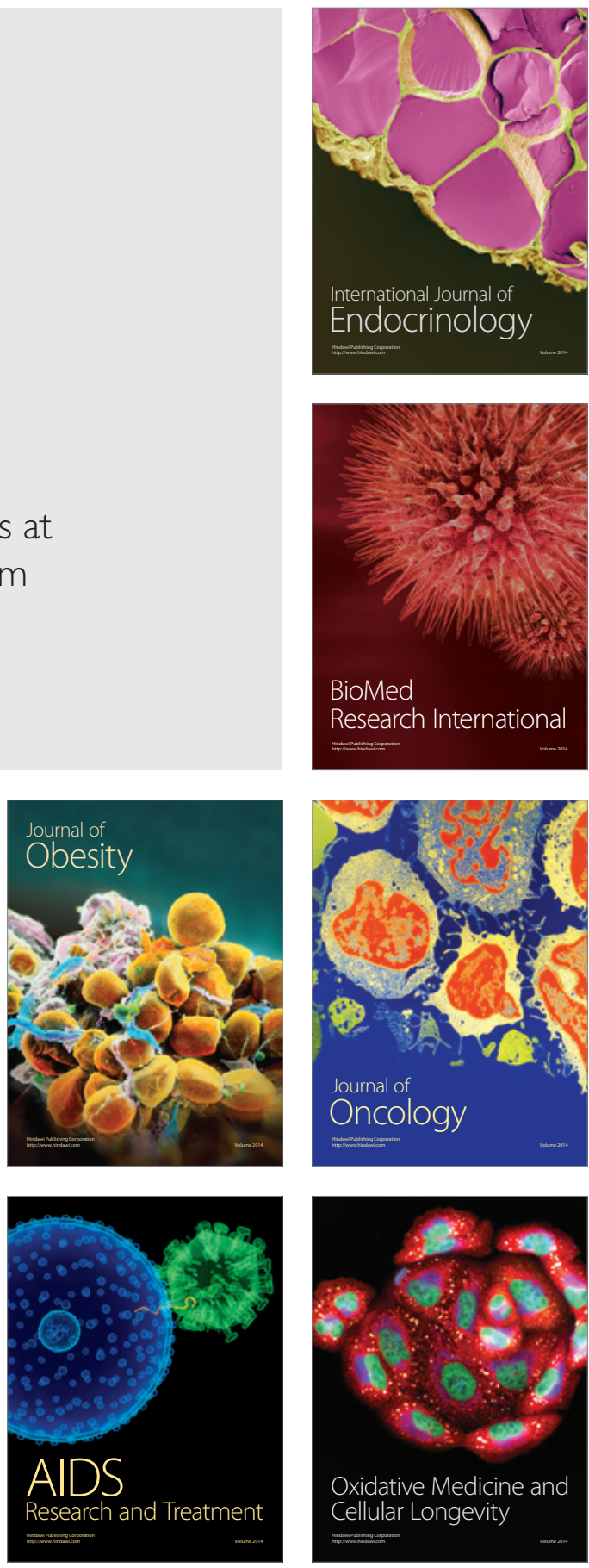